\title{
An Analysis of the Teaching Strategies of the Introduction of Chinese Traditional Culture in Teaching Chinese as a Foreign Language
}

\author{
Cheng Cheng \\ Anshan Normal University 114007
}

\begin{abstract}
In recent years, teaching Chinese as a foreign language has developed rapidly. As the new typical model of language teaching and culture teaching, fully understanding the introduction of Chinese traditional culture is of great significance to the development of teaching Chinese as a foreign language. This paper tries to briefly explain the process of teaching Chinese as a foreign language. On the basis of realizing the significance of traditional culture teaching, this paper also innovates the importance of introducing traditional culture in teaching Chinese as a foreign language, and explores the ways how to pay more attention to and correctly handle the organic relationship and close contact between the language and culture to further discuss the mode, method and principle of the introduction of traditional China culture.
\end{abstract}

Keywords-Chinese teaching; Traditional culture; Traditional element; Teaching strategy

\section{THE CONTENT STRATEGY ANALYSIS OF THE} INTRODUCTION OF CHINESE TRADITIONAL CULTURE IN TEACHING CHINESE AS A FOREIGN LANGUAGE.

The first is the analysis of traditional cultural elements in the language structure. Specifically, it refers that fully reflect the Chinese traditional culture embodied in Chinese through analyzing the key elements such as words, sentences and paragraphs and so on in Chinese language in the process of teaching Chinese as a foreign language [1]. It is usually believed that Chinese language belongs to the type of analytical language and is different from other languages. There are not great changes of the morphologic field in Chinese language words and Chinese language sentences. The important relationship of Chinese grammar is further fully realized mainly relying on Chinese language function words, adverbs and word order. Chinese language is quite different from the tortuous language (make up the complexity of language by rich changing of the person, tense and lattice) represented by English originated from the Indo European language family. It is relatively isolated and is of little change. This requires the language users to fully change related forms of the verbal verbs according to a certain linguistic tense. At the same time, the relevant forms of Chinese grammar need to add some adverbs to the front of Chinese verbs, or add certain mood auxiliaries to the end of Chinese language to help complete and express complex sentences. The second is the analysis of language use elements in the language structure. Specifically, it refers that in the process of Chinese language expression, a situation usually appears, that is, the sentences seem to be the same on the surface, but are of the opposite meaning and connotation. These statements can be correctly understood and applied by being analyzed according to specific historical background and actual application scenarios and circumstances of the language. In many sentences of Chinese language, the literal meaning of Chinese needs to be taken into consideration and the hidden Chinese meaning should be taken into account at the same time. Practice has proved that in the process of daily Chinese language communication, it is hidden in the surface meaning of Chinese language. The conventional deep meaning of Chinese language is very important. If we cannot accurately understand and flexibly use these communication cultures of Chinese language, Chinese language learners will have some obstacles in the flexible use of language and even affect the normal communication and interaction [2]. The semantic constituent elements of Chinese language structure exist in the form of the unit. It can cover related traditional national cultural connotations and main contents and traditional Chinese cultural psychology which can be effectively reflected in this way [3]. In Chinese language teaching, we should give full consideration to the traditional cultural factors hidden in the background of Chinese language semantic and closely linked the traditional cultural elements and the traditional psychological characteristics of Han nationality and national traditional culture as an important means of the introduction of Chinese traditional culture in teaching Chinese as a foreign language. 


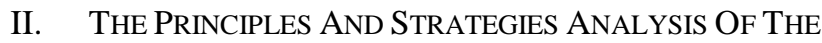 INTRODUCTION OF CHINESE TRADITIONAL CULTURE IN TEACHING CHINESE As A Foreign LANGUAGE.}

The first is the principle of introducing the traditional culture into the service communication. In the process of teaching Chinese as a foreign language, traditional learning methods may cause learners to be inaccurate in understanding Chinese language and even cause communication barriers in Chinese language, which will lead to a large increase in the cost of Chinese learning. According to the actual situation of Chinese language learners in the use of Chinese communication, teachers teaching Chinese as a foreign language need to maximize teaching the Chinese language forms loved by students and pay more attention to teaching the cultural knowledge of Chinese language easier for students to misunderstand or more difficult to understand. Make sure that in the process of learning Chinese language, students have solid Chinese traditional cultural background as the support to successfully achieve the normal communication goal. At the same time, for teachers of teaching Chinese as a foreign language, they should pay more attention to the development of such situations, timely introduce Chinese traditional culture and further enrich the knowledge reserve of Chinese language [4]. The second is the principle of the gradual introduction of traditional culture. Step by step conforms to the basic cognition law of people and it also conforms to the law of language learning. For the teachers of Chinese as a foreign language, they should always adhere to the important teaching principle of "step by step". Distinguish the learning situation at different stages and the actual situation of students at different levels. Effectively carry out and develop education and teaching of traditional culture introduction with different degrees of difficulty. For students whose understanding ability of Chinese language is relatively weak, it is suggested that they should actively take the method of combining the theory and the practice. Make the classroom teaching of Chinese language specific. Make the learning content be from simple to complex, from concrete to abstract. Positively introduce into traditional cultural knowledge and theory closely related to daily life. The third is the principle of introducing the teaching of students in accordance with their aptitude into the traditional culture. For most foreign students, Chinese language and Chinese traditional culture are very strange to them. In the actual process of Chinese language education and teaching, as well as practical communication activities, foreign students will consciously compare and contrast the two totally different cultures [5]. For foreign language teachers, they should fully understand and grasp the important characteristics of the culture of the native language of foreign students in their country. According to teaching objectives of Chinese language and taking the traditional culture of foreign students' native language as the background and the basis, make in-depth comparison of and study Chinese traditional culture [6]. At the same time, insisting on the principle of teaching of students in accordance with their aptitude in teaching Chinese as a foreign language requires to further clarify the main contents of introducing traditional culture and fully meet the actual needs in the teaching of foreign students strictly according to the requirements of specific goal of education and teaching of Chinese language ensure the teaching of students in accordance with their aptitude of Chinese as a foreign language be implemented and accepted and recognized by foreign students.

\section{THE FUNCTION STRATEGY ANALYSIS OF THE \\ INTRODUCTION OF CHINESE TRADITIONAL CULTURE IN TEACHING Chinese As A Foreign LANGUAGE.}

The introduction of Chinese traditional culture is of an important function and role in the teaching of Chinese as a foreign language for the cognitive function of Chinese language learning. As a part of human cognitive function, language is closely related to people's behavior habits and life experience of their own country and nation. When language users describe something, they usually describe or judge things objectively based on their experience and cognition of their society besides objectively describing something. This is the imperceptible influence of traditional culture on language users. In teaching Chinese as a foreign language, the function of cultural introduction is to enable Chinese learners easier to understand how language is endowed with the content beyond the surface meaning by analyzing the context [7]. For example, when a Chinese describes a topic related to eating, it usually does not simply refers to the behavior of "eating". Eating in China can extend a variety of morphological descriptions related to the diet culture, such as social, historical, geographical, and humanistic and so on. As Chinese language learners, if they have enough knowledge of Chinese diet culture, they can have more flexible, accurate and creative associations when using such kind of language. Another typical example comes from Chinese festival culture. Chinese festival culture is formed based on the long and unique history of China. It is endowed with a lot of special cultural attributes. The family attribute is the most important. Many Chinese festivals emphasize the unity and harmony of the family. After learners of Chinese language have a relatively deep understanding of Chinese festival culture, they can naturally understand a lot of language in China about the description of the family and even effectively analyze and learn the derived meaning of abstract statements such as reunion, unity, harmony and so on [8]. Such learning method of conducting the language cognitive function through cultural introduction makes a more profound and three-dimensional structure and level in the teaching of foreign language. 


\section{The Teaching Strategy Analysis Of The INTRODUCTION OF CHINESE TRADITIONAL CULTURE IN TEACHING Chinese As A Foreign LANGUAGe.}

In teaching Chinese as a foreign language, introducing the teaching of Chinese traditional culture in teaching Chinese as a foreign language should always be carried out designedly, by step and systematically from the beginning to the end and study the introducing strategy of traditional culture [9]. Chinese language is the key and important carrier of Chinese culture. The introduction of culture can play an important role cannot be ignored in teaching Chinese as a foreign language. Foreign language teachers actively fulfill the teaching tasks. At the same time, they need to shoulder the important responsibility of the education of the introduction of traditional culture. I. Different national cultures have different values, different beliefs and different opinions on things. Culture is a kind of complex body. It includes knowledge, beliefs, art, morality, customs and other abilities and habits acquired in the society. Therefore, it is necessary for Chinese teachers of foreign language to explain the traditional cultural elements in the classroom from the overall outline and so on and encourage and guide cultural diversification. Train students to more clearly know the truth of the differences of different cultures from the perspective of values, thinking ways and so on. II. At the same time of strengthening the introduction of Chinese traditional culture in teaching Chinese as a foreign language, we need to make the masses of foreign students more deeply and carefully understand the essence and the connotation of China traditional culture. In classroom teaching activities, we can guide the discussion of a specific topic related to traditional cultural, focus on introducing daily lifestyle and daily behavior and promote further understanding of different traditional cultures to better deal with all kinds of different communication problems in language occasions and in-depth understanding of the behavior pattern of Chinese traditional cultural factors in the process of language communication. III. In the classroom, foreign language teachers of Chinese can actively explore and discuss. At the same time of teaching strictly according to the main content of language textbooks, actively carry out a variety of education and teaching activities to make foreign students further clearly identify and compare different characteristics and significant differences between Chinese and their national traditional culture to enhance their interest on Chinese language learning through these activities. IV. Carry out special lectures. For some foreign students with better Chinese, they have had a profound understanding of Chinese traditional culture. The common Chinese culture teaching with social nature has been unable to meet the needs of these students. Then, it is a good choice to carry out some special lectures of flexible topics in time and choose a specific Chinese traditional culture to carry out a longitudinal and indepth explanation. This is also in line with the educational principle of "teaching students in accordance with their aptitude" in previous article. IV. Special research. On the basis of previous methods, the teachers of Chinese as a foreign language encourage and guide students to carry out independent research on special topics. Let the students be passive to take the initiative and choose the subject they are really interest on to carry out systematic research. It can enable students to enter a deeper level of the ability to use and understand Chinese. At present, there may be a lack of learning motivation for this method, which may require schools and teachers to encourage students participating in projects at the level of the policy.

\section{CONCLUSION}

After analyzing the content strategy, principle strategy, functional strategy and teaching strategy of the introduction of Chinese traditional culture in teaching Chinese as a foreign language, we can find that the purpose of teaching Chinese as a foreign language is changing from the initial common communication to intercultural communication at present. Using simple Chinese to mechanically and superficially translate foreign languages has also begun to be unable to meet the learning demands of foreign students coming to China. Nowadays, with the explosive growth of Chinese soft power in the world, China is eager to be recognized by other ethnic cultural groups in the world. And the world also wants to learn more about the ideological behavior pattern and its connotation formed in Chinese culture for thousands of years. And language is a carrier of national culture. It is the cultural essence obtained after many times of tempers by history. Culture also conversely makes language more threedimensional and hierarchical. How to use scientific and systematic way to introduce and integrate culture into teaching Chinese as a foreign language to help learners really understand the deeper meaning of Chinese expressed in the communication process with more simple, more accurate and more efficient mode will be an important research direction for educators of teaching Chinese as a foreign language in the future.

\section{REFERENCES}

[1] Li Jianguo, Yang Wenhui. The Characteristics of Cultural Introduction in Teaching Chinese as a Foreign Llanguage $[\mathrm{J}]$. Journal of Huaqiao University (Philosophy Edition), 1999(3): 95-96.

[2] Zhang Delu. Functional Linguistics and Foreign Language Teaching [M] Beijing: Foreign Language Teaching and Research Press, 2005: 10-11.

[3] Zhao Aiguo, Jiang Yaming. An Introduction of the Applied Language Culturology [M]. Shanghai: Foreign Language Education Press, 2003.

[4] Zhou Xiaobing, Li Haiou. Introduction of Teaching Chinese as a Foreign Language [M]. Guangzhou: Zhongshan University Press, 2004.

[5] Zhao Yongxin. Comparison of Chinese Language Culture and Teaching Chinese as a Foreign Language [M]. Beijing: Language Culture University Press, 1997.

[6] Zhang Huifang, Chen Haiyan. Cultural Teaching Content and Linguistic Cultural Factors in Teaching Chinese as a Foreign Language [J]. Social Scientist, 2006, (3).

[7] Yuan Yumei, Zhang Xinning. Cultural transmission in Foreign Language Teaching [J]. Journal of the College of Adult Education, Hebei University of Technology, 2006, (2).

[8] Xu Jianhua. The Cultural Model Theory of Cognitive Linguistics and Foreign Language Teaching [J]. Journal of Hangzhou University of Electronic Science and Technology (Social Science Edition), 2006, 20(1).

[9] Li Jianguo, Yang Wenhui. The Characteristics of Cultural Introduction in Teaching Chinese as a Foreign Language -- Talking from the Cultural Essence of Language [J]. Journal of Huaqiao University (Philosophy Edition), 1999. (3). 